\title{
Qualimetry of Competences in the University Quality Management System
}

\author{
Elena V. Borisova \\ Research Institute of the Federal Penitentiary Service of Russia \\ Moscow, Russia \\ elenborisov@mail.ru
}

\begin{abstract}
The importance of building an educational results monitoring system in the format of competences was considered and substantiated. Sources, means and approaches to the informational contents of the university quality management system through the qualimetry of competences were shown. Theoretical grounds and implementation methods were specified.
\end{abstract}

Keywords - quality of higher education, competence monitoring, qualimetry of competences

\section{INTRODUCTION}

Quality assurance in the higher education system can be defined as policies, activities and practices. Attempts made by the state to bring the quality of higher education under control in modern Russia began with the development of educational standards, introduction of comprehensive university assessment and stimulation of creation of quality management systems. A global trend towards the development of higher education is to change the uniformity of its social base. Education is becoming widespread and international. Students, persons originally from different social classes and cultural traditions, have an effect on goals and contents with their different requests and prospects of using the acquired intellectual capital. At the same time, individual values and acquired status are moving to the foreground. Furthermore, widespread nature is generally associated with a decrease in quality. Higher education institutions are obliged to prove their justified existence in the educational services market to students, parents, employers, professionals.

The university quality management system is a mandatory requirement in the procedures of state accreditation and public-professional audit. A task to be resolved in the organization and management of the educational process is to adequately relate the labor market's requirements to a contingent of students, thereby ensuring the selection and implementation of relevant management solutions, educational methods and technologies.

The process of monitoring the quality of higher education includes students, teachers, educational institutions and educational systems. The subject of its assessment is primarily students' educational achievements as a measure determined through supervision and related to the compliance of an achieved level with a standard, i.e. requirements of educational standards, statistical standards and consumer requests. There is currently an underestimation of the importance of the system monitoring of competences. This monitoring is often regarded as an optional part of quality monitoring in management processes. At the same time, the consistent implementation of the process approach, one of the eight principles of quality management, assigns a significant independent role to this type of monitoring. A teaching staff and services providing the educational process act as an instrument of this type of monitoring, whereas students do as an object. Educational results based on the competence-based orientation specified new tasks before university-level management institutions. One of them is to create accompanying monitoring systems aimed at tracking the dynamics of student competences in order to obtain forecast estimates and prospects for corrective effects in a timely manner.

The acquisition of competences is a continuous process that is not always unidirectional. During the educational process at university, various competences are acquired, improved, manifested and, at the same time, lost. In this regard, the issue of quantity and timeliness of collected information is being brought up to date. University quality management services have a wide list of used models and functions, but they do not deal directly with the issues of monitoring the formation of competences. This is more due to the complexity of assessing this many-sided educational result. Difficulties arising from competence monitoring procedures are also connected with the considerable volume of additional labor costs for preparing valid control and measuring materials in order to assess various competences, developing and applying special assessment methods and pedagogical techniques, instruments aimed at registering obtained results. Some theoretical prerequisites for resolving these issues are part of the contents of this article.

\section{MethodS AND MATERIALS}

A research task was accomplished on the basis of an analysis of regulatory documents related to next-generation education standards, documents related to the organization and introduction of quality management systems in higher education, literary works on the principles and systems of assessment of educational achievements, academicmethodological packages and working programs in the fields of bachelor's and master's degrees, periodical publications on similar research problems. Special attention was paid to the theory of qualimetry developed in the Research Center of the Quality Problems in Training Specialists. The methodological potential of the issues considered includes an interdisciplinary approach and an index method of assessing complex objects, from the perspective of the qualimetry of competences. 


\section{RESULTS}

The Berlin Communique of the member countries of the Bologna Process states that "consistent with the principle of institutional autonomy, the primary responsibility for quality assurance in higher education is on each institution" [1]. "General quality management is achieved by the systematic improvement of processes, human resource management, strengthening the manager's responsibility" [2, 3].

The provisions embodied in Russian and foreign documents concerning the quality of education primarily deal with "the formation and development of competences, improvement of students' social qualities to effectively interact with other people and realize their potential" [4]. In due course, when creating educational standards in England, the discussion resulted in "a decision to develop a set of special competences for individual programs that would also include common skills" [5]. An audit of academic achievements in the format of competences "develops a culture of monitoring in universities, characterizes a consensus between disciplinary standards, student assessment systems, reflexion and further use of obtained results" [6].

It is difficult to judge of the effectiveness of the educational process in any other way than that considered useful. This fact implies the mandatory inclusion of assessment procedures of forming competences into quality management processes. Such procedures are brought up to date by implementing the individual's properties and, in addition to educational achievements, include "personal characteristics, such as level of aspiration, orientation, goalsetting, emotional-volitional regulation, value-sense attitude" [7].

As early as the 1970s, Russia developed the concept of synthetic qualimetry, a new paradigm of the organization of qualimetry as a science of regularities and methods of measuring and assessing the quality of objects and processes assimilated by human practices. On this methodological basis, the Research Center of the Quality Problems in Training Specialists developed the theory of qualimetry in education as a scientific branch of education studies [8]. Within this paradigm, the assessment of education quality appears as a measure of quality related to the standard of quality in a certain qualimetric scale. The qualimetric approach is considered from the perspective of practical-oriented tactics of the management of formation and development of a quality assessment system for the educational process at university. The approach allows us to extract a maximum amount of information from quantitative estimates obtained and to accept or reject hypotheses, proposals and management schemes put forward with mathematical precision.

Audits in the university quality management system are based on the scientifically organized collection and analysis of student results during the course of education. At the same time, considerable attention was paid to how "the information collection system is built, on what the validity of assessment tools used is based" [9]. Understanding the goals and objectives of monitoring studies against the assessment of students' educational achievements at university helps to determine the structure of a qualimetric complex. The central link of this complex as an integral system is student, his/her achievements expressed, according to the requirements of state educational standards, in terms of competences. The main tasks of competence monitoring are as follows:

- obtaining information about personal qualities;

- obtaining information about levels of competence achieved;

- identifying trends in levels of competence;

- identifying influential factors and recommendations regarding relevant measures.

In terms of the European Higher Education Area, the term "criterion-referenced assessment is defined as a threshold control system and three consecutive stages specified in the Bologna Process (first cycle, second cycle and third cycle), within which all qualifications of the European higher education system are available" [10]. As a result, in the modern sense, higher education is divided into three successive stages: fundamental, general cultural training; general professional training (bachelor's degree); special training of higher qualification (master's degree). According to established traditions, the first basic stage takes place mainly during 1-2 years, the first cycle, a next one, during 3-4 years respectively, the second cycle and the last stage until completion of full education in higher school - the third cycle. The threshold quality control, when passing from one stage to another, may be intermediate (current attestation - self-control) or can be carried out by an educational institution to find out what educational results students achieve at the end of their educational cycle. Specific characteristics, abilities, skills, behavioral units, student grades are developed as criterial indicators determining the threshold of successful passing of a given stage. Let us note that a shortage in one criterial indicator can be compensated for by success in another. This control system is associated with a threshold minimum of achieving educational results [11].

The qualimetry of a competency-based structure of the student's personality is based on the idea of its vocational orientation. In this approach, in order to fully assess the levels of competence formed, it is necessary to measure and take into account all components of the competence concept: personal qualities, knowledge, skills, possessions. The threshold control and correction of personal educational achievements and social qualities are of particular importance. As students progress in higher education, they not only "acquire new academic knowledge, but also form themselves as social persons, developing a set of universal competences that, when taken together, ensure the normal life of a person in society" [2].

Obviously, during primary measurements, students demonstrate self-esteem and a certain type of personality formed at the time being. These personal characteristics cannot remain unchanged not only throughout life, but also during the educational process. The university quality management center is provided with information about each newly enrolled student. At the initial stage, the information system associated with the monitoring process contains 
general information about an admitted student and the results of his/her entrance tests. During an adaptation week, an "input" individual level of universal competences and personal qualities is measured and registered. Further procedures related to the qualimetry of competences are united with one goal: monitoring the quality of education, which is facilitated by processes, tasks, supporting services, analyzable factors and control actions. In the conditions of implementation of modern educational standards, the information system must ensure:

- principles of individualization of data collection and personalization;

- an information basis for the mechanism of selfdevelopment and reflection of all subjects involved in the educational process;

- an integrated and cumulative nature of information that should be transparent, open, objective and expeditious;

- a connection with modern educational technologies and a reasonable balance between external and internal evaluations.

In order to provide the qualimetric complex of monitoring with comprehensive information, it is necessary to carry out qualimetric procedures not only when passing over threshold stages of education, but also according to the modular approach of learning educational disciplines and undertaking practices. The frequency of such measurements is one more issue requiring further study.

As part of the competence monitoring complex, the most significant element is the results of educational achievements. It unfolds into the stages of measurements and calculations of student individual characteristics at the end of which the student's competence-based portrait is built, i.e. a competence profile. Let us note that from a psychological and applied point of view, it is not quite correct to represent the specialist's competence using one numerical value. Moreover, it is difficult to explain what this value reflects. Practical information will carry a final set of values for each competence measured, i.e. a range of personal achievements or a competence profile. The qualimetry of competences will be adequate provided that a comprehensive assessment method is applied, which consists either in summarizing the set of indicators of one classification group or the set of indicators of different classification groups.

The general theory of qualimetry defines the following concepts specified in the aspect of the study in question [12].

Quality indicators are a quantitative characteristic of the object's properties that is considered in relation to certain conditions. Depending on the number of characteristic properties, we will distinguish between single, complex and integral quality indicators.

Single quality indicators are those related to only one of the object's properties (simple property) that can be singled out and assessed independently from others also being a part of the object's quality (indicators).
Complex quality indicators characterize a set of related properties (complex properties) from the whole set of properties forming the object's quality (indexes).

A basic quality indicator is the object's quality indicator taken as a reference in comparative quality evaluations. In order to assess competences, let us take them equal to one.

A relative quality indicator is a relation of the evaluated object's quality indicator to a basic quality indicator expressed in relative units. In the form of such indicators, we will consider the change of individual values of competence indexes at different stages of the educational trajectory.

A complex indicator is a function from single indicators (indicators) and/or complex indicators (previous hierarchical level) and can be represented as:

- a main indicator reflecting functional suitability, i.e. the graduating student's competence;

- weighted averages reducing single and/or complex indicators to one number expressing the object's separate quality (separate competence) with reference to its relative importance.

A state of the phenomenon under study, i.e. a personal competence profile, cannot have absolute accuracy when quantified. This complex portrait is defined by a set of elements, a range and level of competences reflecting the student's qualitative properties. The elements taken into account are quantified by indicators in the structure of the individual competence index. For the elements forming an index set, it is possible to single out two groups of indicators that are conditionally defined as positive and negative. Let us regard positive ones as those from the growth of indicators of which there is an increase in the value of an index. Negative indicators are when the relation between the growth of their values and the index value is inversely proportional. Different competences are formed as $\mathrm{n}$ of modules of academic disciplines is studied. During one "step" of education, for example, a semester, one competence can be formed in different modules and its integral level is determined by the set of formed levels in each of $m$ of modules.

Incoming information is accumulated and analyzed by the qualimetric complex during the whole period of the student's university education. At the final stage of the bachelor's degree program, before preparing a graduate qualification work, the accompanying monitoring system forms a preliminary competence profile for each graduate. This profile is a personal-oriented preliminary result of passing the educational trajectory at university. A final competence-based portrait is created according to the results of final attestation and is recorded in the form of an individual competence profile. This profile includes a list of the graduating student's competences, according to the provisions of a main educational program, and their formed level, according to calculated integral indexes.

Theoretical prerequisites for calculating main and weighted indicators according to a selected set of indicators are considered in the article [13]. It should be noted that in practice the description and measurement of individual 
elements of competences from a general profile displayed in the course of relevant activities provides much more information than some general global assessments. This description, in the form of a competence-based model, differs considerably from a traditional set of scores towards higher adequacy. This non-factor model is based on the assumption that competence "can best be revealed through the individual's values, moral obligations, expectations and representations, as well as those competences that a person tends to show spontaneously, seeking meaningful purposes for himself/herself" [14]. The application of a descriptive characteristics method results in a competence model in the form of a personal competence profile. The graduating student's quantitative-qualitative portrait makes it possible to register different types of competences that are steadily manifested during the whole (or analyzed) period of their formation. This model has no dimension restrictions and can be detailed to the level of separate competences formed in a particular module. It is intended to assess:

- what type of competences the student considers to be a priority for himself/herself;

- what type of competences is not sufficiently formed;

- what types of universal competences help or prevent the student from demonstrating meaningful elements of professional competence.

The considered ideology of building a competence model in the form of a personal competence profile is inextricably connected with the qualimetry of competences, the construction of which is based purely on a mathematical theory. Mathematics is fundamentally abstracted from the properties of specific objects or processes and considers only their ideal models and interconnections between them. Therefore, a mathematical model of the qualimetry of competences can be considered as some abstract system of separate properties having different degrees of complexity.

The requirement of measurable competences as a control subject in the university quality management system is today a significant difficulty, both in theoretical and practical terms. As of today, there are no generally recognized methods of measuring competences in the educational system. This is primarily due to the very nature of the concept as competences are a dynamic combination of knowledge, skills, possessions and abilities (personal qualities).

Competences are formed in different sections (disciplines, modules) of a course of education and assessed at different stages of the educational process by different instruments, teachers. They may be divided into competences relating to a subject matter (professional ones) and universal competences (ones independent from subject contents). Competences are a point of convergence of main vectors of the student's general education and professional training, potential, abilities and motives.

From a psychological point of view, competences should be considered as a complex and newly formed structure based on mutually determinable components: motivational, valuesense, personal, cognitive and activity-related. In the course of education, the development of personal qualities determined by the requirements of a certain profession and the structure of possible positions within that profession is no less important than the acquisition of professional knowledge and possessions. The successful formation of professionally directed competence is based on the higher education subject's personal potential. Therefore, the system of monitoring the formation of competences during the educational program should reasonably include psychodiagnostics of the student's personal qualities at different stages of education, which has been used for quite a long time in the procedures of assessing professional competence in companies.

Competences, as a subject of control in quality management, may be decomposed into two potentially measurable main components exclusively for methodological purposes:

- professionally required knowledge, abilities, skills in activities;

- professionally significant qualities of a person.

Qualimetric operations in the competence monitoring define the quality assessment process in a narrow sense that is revealed through the following set of procedures:

- selecting evaluation indicators;

- dividing evaluation indicators into main and additional ones;

- scaling separate indicators

- folding (combining) indicators, i.e. obtaining a complex indicator;

- assessing the quality achieved on the basis of a complex indicator

The decomposition of measured indicators, otherwise the construction of a hierarchical structure of quality indicators, determines the resolution of such issues as:

- $\quad$ selecting the type of folding (model, assessment)

- selecting a model of complex indicator;

- determining weight coefficients of indicators.

The folding includes the procedures of transitioning from private scales to a general universal one. The qualimetric model of indicator folding into an index estimate is a variation of the linear model proposed by A.I. Subetto [15]. The qualimetry of the student's competences may be adequate provided that a comprehensive assessment method is applied, which consists either in summarizing the set of indicators of one classification group or in the set of indicators of different classification groups.

The proposed index qualimetry of competences is aimed at assessing (measuring) the rate of change in relative indicators (levels) of competences in the base period of time (module, semester, academic year) or at threshold stages of the educational process. At the same time, a measure is a competence index, i.e. a result of the folding of competence indicators. An index is basically a comparison and 
measurement tool obtained from the combination of indicators. During regulatory measurements, index values are used to determine the rate of change (dynamics) in separate competences based on the results of monitoring observations. In addition, they can register, for example, the successful implementation of innovative educational methods and the results of pedagogical staff's reflection. An advantage of complex indicators (indexes) and index qualimetry in general is a possibility of operating and using considerable volumes of statistical measurements for the purpose of analyzing and assessing levels of formed competences. As a result, it is potentially possible to register deep regularities, trends and contradictions in the functioning and development of the higher education system, as well as negative factors, and find tactical and strategic solutions associated with improving the quality of education.

A competence monitoring information support system is created to manage information flows integrated into the educational process. This system resolves the task of how to bring all processes ensuring the quality of university education as close as possible on the basis of modern technologies, network interaction and digitalization of educational contents. In order to implement the monitoring information support system, the following activities should be carried out:

- creating and maintaining an information base of educational resources;

- creating and maintaining an information database of educational subjects;

- organizing a comprehensive subsystem aimed at processing competence monitoring data;

- organizing a comprehensive documentation management subsystem;

- extending the capabilities of operational modular, intramodular control of formed competences.

The system should monitor the progress of the educational process on the basis of systematic data collection and processing, analyze the reasons for change in quality indicators, suggest predictive estimates, identify problemrelated elements, create recommendations on improving educational processes. A task of the qualimetric competence monitoring complex is to consistently control education quality indicators and, in case of their deterioration, timely recognize, determine and eliminate the causes of such changes.

The accompanying monitoring system is provided with information contents by introducing a modular system of education and assessing student competence-based achievements into the educational process. This system contributes to their stable and intensive work during an academic year (semester) and to an increasing role of independent work and reflection. This makes it possible to form an information results bank reflecting educational achievements in dynamics and conduct an analysis for decision-making. So, for example, according to an existing level of access, the following information is displayed upon request:
- regarding each student separately, his/her grades in all controlled activities, values of complex indicators and threshold competence-based assessments;

- first (best) $\mathrm{n}$ of students based on the value of a complex indicator (competency index);

- students achieving the highest indicators within the whole range of competences;

- students having the highest indicators in separate types of competences;

- students showing the best dynamics of competence formation

- last $\mathrm{n}$ of students based on the value of a complex indicator (competency index);

- students showing the worst dynamics of competence formation, etc.

In the design of quality management processes from the perspective of formation of a set of competences specified by qualification requirements there is an idea of quality education in the aspect of a subject-to-subject approach. An important part of this approach is the qualification and training of teaching staff. Qualitative organizational and pedagogical effects contain not only modern technologies, methods and innovations, but also scientifically based instruments for monitoring student educational achievements in the format of competences. The teacher should not only be aware of the importance of monitoring measurements, but also should possess evaluation tools and corrective techniques, analyze intermediate results, predict them for compliance with goals, correct pedagogical methods and technologies, reflect on the issues of professional improvement.

\section{CONCLUSION}

The new generation of state educational standards is focused on achieving an individual maximum. They should provide each student with an individual bar, the level of which will indicate the quality of his/her education. The university quality management system should monitor the progress of the educational process on the basis of purposeful collection and processing of current information, analyze the reasons for change in current and threshold quality indicators. A task of qualimetric competence monitoring, as one of management subsystems, is to consistently measure monitored indicators and, in case of their deterioration, timely recognize, determine and eliminate the causes of such changes. The expert community specializing in education quality assessment is increasingly inclined towards the format of audits [6]. Their advantage is the conceptual reliance on the results of regular monitoring measurements and student reflexion.

The results of the conducted study are an attempt to reasonably answer the question about methods and tools for obtaining relevant information on the levels and trends of formation of student competences. The results reflect both the very existence of various methodological issues and possible, theoretically supported methods of their resolution. It is important to underline once again the role and responsibility 
of pedagogical staff in competence monitoring processes. It is teachers who: implement competence-oriented methods of giving classes; develop relevant pedagogical technologies and adequate control-measuring materials to assess the established levels of competences within disciplinary modules; correct the forms and methods of education. It is important to ensure that the competence monitoring system is balanced and that results are realistic.

The effective competence monitoring system in the university quality management system is intended to unite the work of all interested persons into a single whole aimed at achieving common goals.

\section{References}

[1] Berlin Communiqué. Retrieved from: http://www.russia.edu.ru/information/legal/law/inter/berlin/

[2] Yu. Pokholkov, A. Chuchalin, Quality management at university. Moscow: Logos, 2004, p. 206.

[3] W. Deming, Out of the crisis. Cambridge University Press, 2000, p. 524.

[4] The framework of qualifi cations for the European higher education area. Retrieved from: http://www.ond.vlaanderen.be/hogeronderwij s/bologna/documents/Framework_qualifi cationsforEHEA-May2005.pdf

[5] G. Williams, "Subject Benchmarking in the UK", Public Policy for Academic Quality: Analyses of Innovative Policy Instruments. Dordrecht, London: Springer, 2010, pp. 157-183.
[6] W. Massy, "Education Quality Audit as Applied in Hong Kong", Public Policy for Academic Quality: Analyses of Innovative Policy Instruments. Dordrecht, London: Springer, 2010, pp. 203-227.

[7] I. Zimnyaya, Key competences as a result-objective basis for a competence-based approach in education. Research Center of the Quality Problems in Training Specialists, 2004, p. 40.

[8] A. Subetto, Ontology and epistomology of the competence-based approach, classification and qualimetry of competences. Research Center of the Quality Problems in Training Specialists Saint Petersburg, 2006, 72 p.

[9] D. Dill, M. Beerkens, Public Policy for Academic Quality: Analyses of Innovative Policy Instruments. Dordrecht, London: Springer, 2010, p. 335.

[10] Glossary of Terms of the European Higher Education (updated version) Retrieved from: http://www.rudn.ru/=pagec=568, 2006.

[11] Implementation of the Bologna Process in the Tempus countries, vol. 2. Brussels, 2010, p. 69.

[12] M. Keleichik, Qualimetry: student's book. Moscow: MGIU, 2003, p. 198.

[13] E. Borisova, "Qualimetry of competences. Theoretical prerequisites", Tver State University Journal. Series: Pedagogy and Psychology, vol. 35, pp. 68-73, 2010.

[14] J. Raven, Pedagogical Testing: Problems, Misconceptions, Perspectives. Moscow: Kogito-Tsentr, 2001, p. 142.

[15] A. Subetto, Introduction to the qualimetry of higher school, vol. 4. Research Center of the Quality Problems in Training Specialists Moscow, 1991, p. 163. 